\title{
Multiple Intelligences and Success in School Studies
}

\author{
Roman Yavich $^{1} \&$ Irina Rotnitsky ${ }^{2}$ \\ ${ }^{1}$ Department of Mathematics, Ariel University, Ariel, Israel \\ ${ }^{2}$ School of Education, Ariel University, Ariel, Israel \\ Correspondence: Roman Yavich, Department of Mathematics, Ariel University, Ariel, Israel.
}

Received: July 3, 2020

Accepted: September 1, $2020 \quad$ Online Published: September 18, 2020

doi:10.5430/ijhe.v9n6p107

URL: https://doi.org/10.5430/ijhe.v9n6p107

\begin{abstract}
The applications of multiple intelligence theory in education are wide. Students apply the learning in the classroom according to their own dominant intelligence and learning style, which is most effective for them. Combining learning styles with dominant intelligences enhances the students' learning processes.

The purpose of this case study is to examine the relationship between dominant intelligences according to Gardner's multiple intelligence theory and middle school students' academic achievement. A case study was conducted in Israel, in a middle school, among seventh-graders and involved 158 students.

Findings indicated that in excellent classes - 80.9\% of students had logical intelligence, in at least one of the levels of dominance; in ordinary classes only $48.4 \%$ of students have logical intelligence, at least in one of the levels of dominance. We also examined the relationship between the amount of dominant intelligences among students in all classes, excellent and ordinary. Findings indicated that in excellent classes the percentage of students with two or three dominant intelligences was higher than the percentage in ordinary classes. It is important to note that these are not just the logical and verbal, but also all types of intelligences, such as spatial, musical, kinetic and others.

In conclusion, the dominant intelligences that highly influence and measure achievement in the education system are not the logical-mathematical and the linguistic-verbal, but the only logical-mathematical. Moreover, the amount of intelligences at the dominant levels can predict and indicate student's success at school.
\end{abstract}

Keywords: multiple intelligences, dominant intelligences, multiple intelligences, and academic success

\section{Introduction}

Gardner's Multiple Intelligence Theory (1983) challenged the educational world. Based on previous studies, Gardner has defined seven intelligences, each at the core of cognitive information processing models (Weller, 1996). Teaching through an approach customized to multiple intelligence theory allows students to develop and enhance various intellectual skills. Gardner and Stenberg (1988) argued that through enriching learning experience, teachers would increase learners' personal motivation (Weller, 1996).

Applications of the Multiple Intelligence Theory in the field of education is wide. At the same time, the main emphasis in education is made only on two intelligences: logical-mathematical and linguistic-verbal, in both teaching and assessment. The use and application of additional intelligences is possible in a different learning environment and a learning method that incorporates the use of additional intelligences (Barrington, 2004).

Continuing on Gardner's multiple theory of intelligence, educators distinguish different learning styles among students. Each student applies the material taught in the classroom according to his or her dominant intelligence and learning style with which a student learns most effectively. Combining learning styles with dominant intelligences according to Gardner's multiple intelligences theory (MI), enhances learning processes among the students (Sener \& Cokcaliskan, 2018). At the same time, multiple intelligence theory focuses on an active learning process and active learning methods in a variety of ways. Teaching based on the student's preferred learning style can promote and enhance the learner's skills and strengths (Calik \& Birgil, 2013).

The purpose of the case study was to map the dominant intelligences among the students attending school in the center of the country, in order to enhance school teaching. First, we decided to examine the population of learners among seventh graders. Students' age was selected based on the school needs. $7^{\text {th }}$ graders that come from different elementary schools, and new students at school. A case study was conducted in a middle school in Israel and 
included 158 students of different achievement levels and different backgrounds. Students attend six classes, two of which are classes with high to very high achievers, and four classes with a heterogeneous learner population: including, high, medium, and low academic achievers. In accordance with the data obtained, it was decided to convert learning according to the dominant intelligence of the learners. A questionnaire examining the learner's dominant intelligence was sent digitally to all students.

\subsection{Multiple Intelligence Theory (MI)}

Gardner's theory of multiple intelligences is based on the definition of the concept of intelligence as the ability to solve problems, and to create a product in several ways (Gardner, 1983). This theory constitutes a theoretical foundation for vocational education, student-based teaching and personalized teaching; it is a basis for multidimensional assessment and a foundation for developing entrepreneurial skills (Yang, 2013).

In his book, Gardner characterized 7 main forms of intelligence: linguistic-verbal, logical -mathematical, musical, spatial, bodily-kinesthetic, interpersonal, intrapersonal. Later in his work, Gardner added an additional intelligence to the list (Gardner, 1999; Tirri et al., 2008) - spiritual. In the second edition of his book, Gardner added an additional intelligence (Calik \& Birgil, 2013) - existential.



Figure 1. Gardner's Multiple Intelligences

Researchers argue that each type of intelligence can be associated with unique characteristics that define it (Berrington, 2004) (Table 1):

Table 1. Characteristics of Multiple Intelligence

\begin{tabular}{ll}
\hline Type of intelligence & Characteristic of intelligence \\
\hline Linguistic / Verbal & $\begin{array}{l}\text { The ability to use language, the sensitivity to word and phrase order, and to verbal } \\
\text { meaning }\end{array}$ \\
$\begin{array}{l}\text { Logical / Mathematical } \\
\text { Musical }\end{array}$ & $\begin{array}{l}\text { The ability to deal with patterns, identify relationships and solve problems } \\
\text { The ability to recognize and detect sounds in the environment, the sensitivity to pitch, } \\
\text { melody, tempo and sound intensity } \\
\text { The absorbing ability of the visual world, the sensitivity to images and visual memory }\end{array}$ \\
Spatial & $\begin{array}{l}\text { The high coordination ability, the ability to operate technological tools } \\
\text { Bodily Kinesthetic }\end{array}$ \\
Interpersonal & $\begin{array}{l}\text { The ability to understand and sympathize with people, create social relationships, solve } \\
\text { conflict } \\
\text { The high personal awareness and personal motivation }\end{array}$ \\
Spiritual / environmental & $\begin{array}{l}\text { The ability to understand the world around them, high contemplation } \\
\text { The ability to ponder questions about life, death, and reality: "Who are we?", "What is } \\
\text { Existential }\end{array}$
\end{tabular}

Key principles of multiple intelligence theory are based on the following arguments (Gouws, 2007):

- Each person has many intelligences and not only one.

- Each person is a unique and has a dynamic set of intelligences.

- Intelligences vary according to personal development and to human environment. 
- All intelligences are dynamic.

- Multiple intelligences are configurable, descriptive and measurable.

- Everyone deserves the opportunity of recognition and development of the multitude of intelligences.

- Using one intelligence can improve and enhance another intelligence.

- All intelligences provide alternative sources for personal development, regardless of age or circumstances.

- Pure intelligence is almost non-existent.

- Most developmental theories also apply to the development of the multiple intelligences.

The development of multiple intelligences among students is highly dependent on many factors, such as gender, age, marital status, parental education, parental involvement, academic achievement, etc. (Tsai, 2016). In addition, the main assumption is that intelligence does not develop as single, static, and monolithic. The opposite is correct. Also, the development of multiple intelligences additionally depends on the cultural and social environment (Bordei, 2017).

Previous study examined the distribution of intelligences among middle school students in seventh and eighth grades, depending on gender and achievement. The results of the study indicated:

- In seventh grade: 159 students participated, 81 boys and 78 girls. Boys received the highest score in interpersonal intelligence and the lowest grades in assessment of linguistic intelligence. Girls received the highest scores in assessment of interpersonal intelligence and the lowest scores in spiritual intelligence. Mapping of the intelligences among all students showed the following scale of grades (from the highest to the lowest): interpersonal, interpersonal, mathematical-logical, musical, spatial, existential, linguistic, kinetic, and spiritual.

- In eighth grade: 156 students participated, 64 girls and 92 boys. Boys received the highest score in logical-mathematical intelligence and the lowest score in spatial intelligence. Girls received the highest score in interpersonal intelligence and the lowest score in the kinetic intelligence. The rank of intelligences among all eighth-grade students showed the following structure (from high to low): interpersonal, logic, interpersonal, existential, musical, linguistic, spatial, spiritual, and kinetic.

The application of these intelligences in a curriculum is significant (Berrington, 2004). Barrington argued that in higher education and non-secondary education, the emphasis is only on two intelligences: linguistic/verbal and logical/mathematical. Assessment is also done on the basis of these two intelligences only. These intelligences dictate the academic ability of learners (Tsai, 2016). The compilation of additional intelligences in curriculum does not allow students with different of linguistic and mathematical intelligences to fulfil themselves and they fail in academic studies. In addition, their abilities and talents sometime remain undisclosed (Campbell et al., 1996). Teaching and learning in tandem with multiple intelligences theory allows students to develop a personalized learning process and to express their ability, strengths and talents in both the process and the learning product (Berrington, 2004).

Recently, the main demand of educators is to teach beyond the two accepted intelligences (mathematical-logical and linguistic-verbal). It is widely believed that the application of the multiple intelligences theory in a classroom will enable educators to change teaching methods and strategies, and adapt them to children's differences (Gouws, 2007).

Each kind of intelligence influences the unique traits of the learner and the future of the mature person. People usually choose a profession that expresses their strength and personal talent. Gardner argued that out of eight defined intelligences, the intelligences that define a leader's personality are interpersonal, intra-personal intelligence, and verbal intelligence (Wilson, 2018). Linguistic intelligence involves being sensitive to the written and spoken language, combined with the ability to use language in order to achieve goals and objectives. Interpersonal intelligence is the ability to understand and make decisions between the emotions, beliefs, intentions, motivations and desires of others, and ultimately to communicate effectively with other participants. Intrapersonal intelligence refers to self-focus and self-control, personal motivation to achieve a goal, and persistence in goals (Wilson, 2018).

\subsection{Multiple Intelligences and Different Learning Styles}

All students differ in their levels of motivation, in their approaches to teaching and learning, in their responses to particular learning environments and in their teaching practices. Educators in all fields are becoming aware of the importance of understanding how individuals learn from the environment. The learners' learning process impacts the teaching strategies, academic performance and learning outcomes (Jena, 2018). Felder and his colleague noted three aspects that influence the teaching and learning processes of students (Felder \& Brent, 2005): 
- Differences in learners' learning styles - the way that characterizes absorption and information processing.

- Attitude to learning - Learning strategies.

- Level of intellectual development - approach to learning and assessment materials.

The general consensus among researchers is that there exists a multitude of learning styles among different individuals (Jena, 2018). The purpose of teaching is to equip learners with skills related to all learning styles, regardless of personal preference (Felder \& Brent, 2005). Learning styles are defined as the way students perceive and process information in learning situations. They site seven major learning styles: visual, auditory, tangible, literal, logical, group, and individual (Sener \& Cokcaliskan, 2018). Students' learning abilities improve as they become aware of their individual learning styles. Learning processes can be enhanced when teaching styles are consistent with learning styles. At the same time, the goal is not to "tailor" a solution for each student, but to develop learning skills among learners appropriate for all types of learning (Felder \& Brent, 2005).

Researchers cite a number of different learning styles and characteristics (Table 2):

Table 2. Learning styles and characteristics

\begin{tabular}{lll}
\hline Learning style & Indicators & Characteristics \\
\hline Visual students & $\begin{array}{l}\text { Prefer learning methods that combine } \\
\text { visual aspects, such as presentations, } \\
\text { pictures and others (Jensen \& Calvert, }\end{array}$ & $\begin{array}{l}\text { These students are influenced by the teachers' } \\
\text { body classroom (Sener \& Cokcaliskan, 2018). }\end{array}$ \\
2014) & $\begin{array}{l}\text { Perceive the environment with the sense } \\
\text { of hearing: music, sounds, words (Jensen } \\
\text { \& Calvert, 2014) }\end{array}$ & $\begin{array}{l}\text { These are affected by the volume, frequency } \\
\text { and speed of speech. These students love to } \\
\text { read in class (Sener \& Cokcaliskan, 2018). }\end{array}$ \\
students & $\begin{array}{l}\text { Prefer verbal learning: writing and } \\
\text { speaking (Jensen \& Calvert, 2014) }\end{array}$ & $\begin{array}{l}\text { These students emphasize what they read, } \\
\text { make notes while listening (Sener \& } \\
\text { Verbal students }\end{array}$ \\
& & Cokaliskan, 2018).
\end{tabular}

Intangible Prefer learning ways that combine students movement, movement integration, and tactile sensation, such as: using hands (Jensen \& Calvert, 2014)

These learners collect the information through the interaction with the physical and motion world. They need a contact for learning and to engage with their hands in different ways. They have difficulty in processes that require extended focus (Sener \& Cokcaliskan, 2018)

Group students Prefer group activities and learning through social interaction (Jensen \& Calvert, 2014)

These students have very good communication skills, both verbally and non-verbally. They prefer to teach and guide others (Sener\& Cokcaliskan, 2018).

Individual Prefer self-study and self-motivation, and students are able to gauge their learning efforts (Jensen \& Calvert, 2014)

These learners have good focus abilities and are aware of thought processes. Students who learn individually are able to express learning process and express personal feelings (Sener \& Cokcaliskan, 2018).

Logical students Look for cause and effect: A learning process occurs when a logical connection is formed with what is being learned These learners are able to analyze different ways of thinking Sener\& Cokcaliskan, 2018).

(Jensen \& Calvert, 2014).

The more teachers understand the differences and the distinctions, the more likely they are to reach most students (Felder \& Brent, 2005). To the extent that the educational team maps learners, according to the different classes of intelligences, the subject taught is implemented optimally and effectively for all learners, and not only those who succeed in math and language (Sener \& Cokcaliskan, 2018). As mentioned above, learning styles are experiential, behavioral and cognitive characteristics that indicate how learners perceive, interact, and respond to learning environments. Some learners are comfortable with theories, abstractions, others with facts and observations, some prefer active learning, and others prefer a visual display of information or oral explanations. The optimal teaching 
method balances all learners, even those that are incompatible - and some students do feel uncomfortable - forcing them to adapt to situations they might need in the future (Felder \& Brent, 2005).

According to Gardner's theory, characterizing a learning style along with a dominant intelligence is essential. It is important for the student to be aware of both the learning style that is most effective for him and his dominant type of intelligence (Sener \& Cokcaliskan, 2018). The theory of multiple intelligences can be applied through the content learned and the guided activity, and can significantly improve learners' participation. Early studies indicate that the use of instructions tailored to the multiple intelligences theory contributes to the development of logical, critical and creative thinking abilities, as well as the development of high levels of thinking (Calik \& Birgil, 2013).

The greatest contribution of multiple intelligence theory in the field of learning strategy development is that educators are forced to expand teaching strategies and tools, and adapt them to the previously logical and linguistic intelligences (Stanford, 2003). Gardner's multiple intelligences theory assumes that there is a variety of human intelligences. Nonetheless, Gardner argues that individual intelligence does not affect skill development, but a combination of several intelligences together affects learners' abilities and, in particular, their ability of dealing with challenges and problem solving. An effective learning process requires critical thinking, so it is important to develop a teaching approach that enhances the learner's abilities. One of the creative ways to do so is to apply Gardner's multiple intelligence theory (Wilson, 2018). The central assumption is that there is a cognitive field of knowledge linked to the type of personal intelligence. For example, logical intelligence communicates academic capabilities and others. Accordingly, the different types of intelligences can be applied to teaching processes, where teaching is based on student skills and aims to advance students' personal abilities (Yang, 2013).

Yang argues that the key in the teaching process is to provide the student with space and opportunity to showcase personal talent. As students grow and develop, they are exposed to a huge amount of information and learn different fields of knowledge. Their intelligences improve through their learning experiences (Tsai, 2016). Personal cognitive abilities enable students to integrate existing perceptions and knowledge into new ideas. Previous experiences invite ongoing development, creativity, and enabling linking and connecting to ideas that were not taken into account in previous situations (Politis, 2005). Students should be integrated into practical and concrete activities; They should participate in implementation, planning and evaluation processes. It is important to enable students to perform interdisciplinary tasks that require collaborative work and teamwork. The role of the teacher in the classroom is not a leading role, but an accompanying one. In addition, students need to know and feel that they are responsible for their own learning, along with the ability to be free to come up with ideas and develop them into actions (Leffler, 2009).

Multiple Intelligence Theory emphasizes that there is no particular set of teaching or learning strategies that fit all learners. Each student has a different tendency within the eight intelligences, and therefore a particular strategy will be successful among one group of learners, and will be less successful among the other groups. For example, teachers who use different rhythms, songs and strings, as classroom teaching tools, will find that students with musical intelligence respond actively, but the rest remain indifferent (Stanford, 2003). Similar response can be seen to using images or characters; Students with visual / spatial intelligence respond to this learning strategy, but students with linguistic intelligence do not. Students need to experience learning that incorporates all the multiple intelligences and allows them to experience the dominant intelligence. Learners need to know how to develop and utilize all existing intelligences for effective learning; It is important to recognize and develop the full range of personal intelligences (Gouws, 2007).

\subsection{Multiple Intelligences and IQ Intelligence Tests}

Gardner's Multiple Intelligence Theory challenges the concept of IQ in at least three ways (Gouws, 2007):

- A significant learning process includes the involvement of several intelligences, not only one. For instance, graph designing involves both spatial and logical-mathematical intelligence, playing the piano requires the use of not only musical intelligence, but kinetic, intrapersonal and interpersonal intelligences (Bordei, 2018).

- Intelligences are expressed by learners' functioning, learning outcomes and personal ideas, not only by exam results. For instance, according to Gardner, the intelligences that characterize a leader's personality are: verbal intelligence, interpersonal intelligence, and intrapersonal intelligence (Wilson, 2018).

- Ways in which multiple intelligences are expressed among learners depend on students' factors such as: cultural background, social and cultural environment. Combination of the intelligences in action is noticeable when combined together in daily actions and in real life (Bordei, 2018).

Gardner does not deny the existence of an IQ, but questions its importance outside of a relatively narrow and limited school system. The result of the IQ test relies almost entirely on two main intelligences: logical and verbal. The basis Published by Sciedu Press 
for the theory of multiple intelligences is that each individual has capabilities above and below these two intelligences measured in IQ tests. Accordingly, these additional capabilities enable thoughtful solution processes, product creation, or the provision of essential services to the society (Gouws, 2007).

\subsection{Contribution of Multiple Intelligence Theory to Collaborative Learning}

The contemporary world trends are teamwork and collaboration. Many partnerships in various areas of development allow faster and more meaningful results. Individual strengths, skills and learning styles are expressed by and contribute differently to the collaborative learning process and teamwork. Roles in the team are usually divided according to the intelligence of the team members. A similar process also occurs in classrooms. Individual learning moves away and collaborative learning occurs instead, when the role of each student in the group is built on their ability and contribution to achieving the team goal; on the talent and strength of each student (Calik \& Birgili, 2013).

Verbal abilities (linguistic intelligence) are more prominent in brainstorming processes, researches, conflicts or discussions, and script building. Students with this intelligence contribute to the formulation of a problem and its solution, drafting work documents, drafting and explaining the work steps (Green et al., 2005). Students with logical-mathematical intelligence have more influence on defining steps to solve the problem. Furthermore, they contribute to formulating the optimal solution that includes a structured way of thinking (Martin, 2001). Students with spatial intelligence have the ability to translate mental and visual models into meaningful models for the rest of the group. For example, translating graphs into verbal results, seeing spatial models, and translating into more abstract figures (Green et al., 2005). Students with kinetic intelligence are more prominent when learning requires the activation of tools, in learning hands-on processes or learning through practice (Martin, 2001). Musical intelligence is expressed in a musical environment (songs, sounds). In addition, students with this intelligence are more notable in learning processes that incorporate the use of sounds or auditory information. Absorption and discernment abilities of intent, motivation and emotion are expressed among students with interpersonal intelligence. These students tend to foster meaningful relationships between team members and collaborative work among team members (Green et al., 2005). Students with intra-personal intelligence are more aware of their abilities, strengths and weakness; they are able to show team members where they need support and where progress can be made. Students with environmental intelligence tend to look at other ways for more creative and environmentally friendly solutions: both social and spatial-environmental (Green et al., 2005).

Each group is unique because of the different people that make it up, just as people are different due to the variety of dominant intelligences. We believe that just as a group works efficiently and creatively, and therefore, the collaborative work products are better, so are students; the more dominant the intelligences are, the higher their achievements.

\section{The Method-Case Study}

A case study was conducted in a junior high school in the State of Israel among seventh graders. A digital questionnaire, that examines the set of dominant intelligence, was sent to the students. Each intelligence was characterized by ten questions, with each question asking students to rate their answer from one (strongly disagree) to four (strongly agree). The sum of the ratings on questions related to a particular intelligence was the score that indicated the dominance of that intelligence. It is important to note that students were not aware of the purpose of the questionnaire and the intelligence to which the question related.

\subsection{The Study Population}

The case study was attended by 158 seventh grade students $(\mathrm{N}=158)$. This age stratum includes six classes:

- "Moffet" class - an outstanding class in the fields of physics and mathematics. Students enrolled in this class have passed preparatory and entrance exams in math, physics and English. Exemplary behavior was a critical criterion to be accepted to this class.

- ST class - a technological science class. This class includes students whose success in math, science and technology in elementary schools has influenced their acceptance into that class, along with the behavior criteria.

- Four ordinary (heterogeneous) classes - classes containing students from around the city. Classes are taught according to the regular curriculum dictated by the Ministry of Education, without any special emphasis. Note that the students in these classes are heterogeneous in grades and achievements. 


\subsection{The Questionnaire}

The Multiple Intelligence Diagnostic Questionnaire was conducted by Mackenzie (Mackenzie, 2002) and translated into Hebrew. The questionnaire contains 80 different questions, each question referring to one of the multiple intelligences according to Gardner's theory. Examples of questions:

- My life was sadder without music (musical intelligence)

- I like to fish, to work in the garden and to cook (kinetic intelligence)

- I follow of developments in the field of science (environmental intelligence)

- I have a set goals and I spend time planning how to achieve them (logical intelligence)

- When I see a problem, I usually ask for help from others before dealing it myself.

- I like to play verbal games (verbal intelligence)

- I like to do puzzles, play maze games and other visual games (spatial intelligence)

- I recover quickly from my failures (Intellectual Intelligence)

In each question, students rated each sentence between one - strongly disagree, to four - strongly agree. The sum of points in each of the intelligences determined the degree of intelligence dominance. The maximum score that can be obtained for each intelligence is forty, and the minimum - twenty, so intelligences that had been given a score below twenty-five did not enter data analysis; intelligences that received the same score or one-point difference entered the same rank of dominance.

\subsection{Case Study Questions}

The questionnaire was sent to students through learning management systems. In receiving the students' answers, we examined several aspects:

1. Which are the most dominant intelligences (level 1), what are the second dominant intelligences (level 2), and what are the third dominant intelligences (level 3).

2. What are the amount of dominant intelligences at Level 1 and Level 2 among students? Are there any differences between students at different achievement levels?

The following are the findings.

\section{Findings}

\subsection{Dominant Intelligences}

We divided the study population into two categories: students in regular classes and students in excellent classes (Moffet and ST): 63 students in the excellent classes (students that study at two classes) and 95 students in the regular classes (students that study at four classes). We examined the number of students with logical intelligence on at least one of the levels (from 1 to 3). The data indicated that:

In excellent classes - 80.9\% of students have logical intelligence in at least one of the levels of dominance. In ordinary classes $-48.4 \%$ of students have logical intelligence in at least one of the levels of dominance.

Since Level 3 refers to the less dominant intelligences, we examined the percentage of students with dominant logical intelligence at Level 1 or Level 2 and the difference between excellent classes and ordinary classes: in excellent classes - $67 \%$, while $41 \%$ in ordinary classes.

Students of the Moffet class, unlike ST class students, passed examinations and acceptance tests in the fields of mathematics and physics (logical intelligence is essential to success in these subjects), therefore, we examined the percentage of students with logical intelligence in at least one of the dominant levels in the Moffet class only (Table 3):

Table 3. Existing logical intelligence in dominant levels

\begin{tabular}{lll}
\hline \multicolumn{1}{c}{ Existing logical intelligence at dominant levels } & Percentage of students \\
\hline At least in one of 3 levels & $85.7 \%$ & \\
At least in one of 2 levels (first and second) & $71.4 \%$ & \\
In first level & $53.5 \%$ & \\
\hline
\end{tabular}


As mentioned in previous studies, the two intelligences that influence success in learning are logical/mathematical and verbal/linguistic. Following this, we examined the dominance of linguistic intelligence among students at one of the dominant levels. Findings are presented in the following table (Table 4):

Table 4. Existing linguistic intelligence in dominant levels

\begin{tabular}{lrrrr}
\hline $\begin{array}{l}\text { Existing linguistic } \\
\text { intelligence } \begin{array}{r}\text { at } \\
\text { dominant levels }\end{array}\end{array}$ & $\begin{array}{r}\text { Percentage of students } \\
\text { in moffet class only }\end{array}$ & $\begin{array}{r}\text { Percentage of } \\
\text { in } \begin{array}{r}\text { students } \\
\text { excellence } \\
\text { classes }\end{array}\end{array}$ & $\begin{array}{r}\text { Percentage of students } \\
\text { in ordinary classes }\end{array}$ \\
\hline $\begin{array}{r}\text { At least in one of 3 } \\
\text { levels }\end{array}$ & $32.1 \%$ & $17.46 \%$ & $14.7 \%$ \\
$\begin{array}{l}\text { At least in one of } 2 \\
\text { levels (first and } \\
\text { second) }\end{array}$ & $\% 7.1$ & & \\
In first level & $\% 3.5$ & $6.3 \%$ & $6.3 \%$ \\
\hline
\end{tabular}

The percentage of students with linguistic intelligence in one of the dominant levels is significantly lower than the percentage of students with logical intelligence, not only in the ordinary classes, but also in the excellent classes.

\subsection{The Amount of Dominant Intelligences}

As mentioned, each student is unique because of the special set of the personal intelligences according to the MI theory. Therefore, a successful team is made up of individuals with different intelligences. Can the multitude of dominant intelligences, at least in one of level of dominance, predict and indicate success in schooling? We tested the amount of dominant intelligence of the students in ordinary classes and excellent ones. For the findings, we focused on two of the highest scores of dominances: first and second levels. Table 5 shows the number of intelligences among Moffet students only at the first and second levels of dominance.

Table 5. Amount of intelligences in 1st and 2nd levels among Moffet students

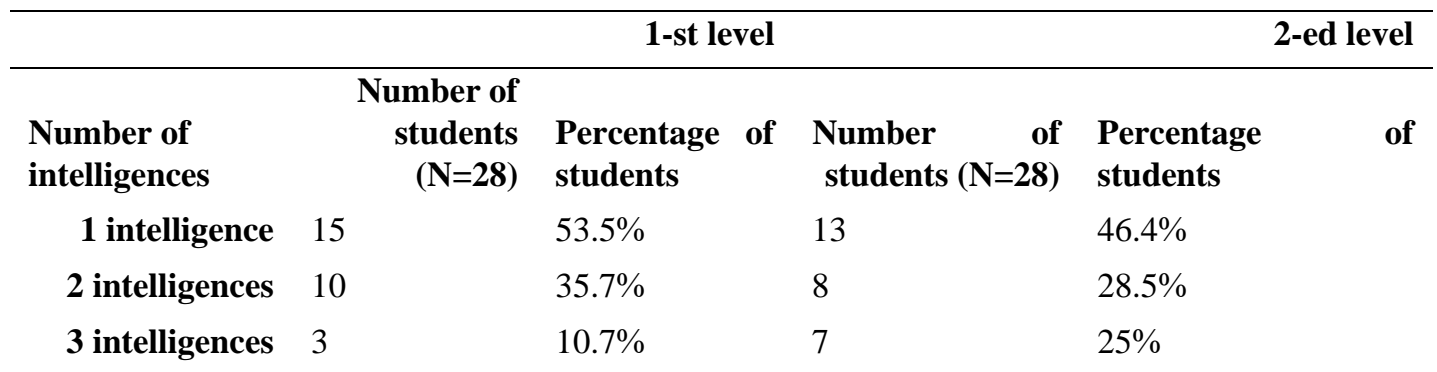

We also examined the relationship between the multiple intelligences among students in all classes: excellent $(\mathrm{N}=95)$ and ordinary $(\mathrm{N}=63)$ classes (Table 6).

Table 6. Percentage of multiple dominant intelligences

\begin{tabular}{|c|c|c|c|c|}
\hline & \multicolumn{3}{|c|}{ 2-ed level } & 1-st level \\
\hline & $\begin{array}{ll}\text { Percentage of } \\
\text { students in } \\
\text { ordinary classes }\end{array}$ & $\begin{array}{l}\text { Percentage of } \\
\text { students in } \\
\text { excellent classes }\end{array}$ & $\begin{array}{ll}\text { Percentage of } \\
\text { students in } \\
\text { ordinary classes }\end{array}$ & $\begin{array}{l}\text { Percentage of } \\
\text { students in } \\
\text { excellent classes }\end{array}$ \\
\hline $\begin{array}{c}\text { Amount of } \\
\text { intelligences }\end{array}$ & $66.3 \%$ & $57.1 \%$ & $60 \%$ & $42.8 \%$ \\
\hline 1 intelligence & $20 \%$ & $44.4 \%$ & $21.05 \%$ & $34.9 \%$ \\
\hline 2 intelligences & $1.05 \%$ & $3.2 \%$ & $4.21 \%$ & $19.04 \%$ \\
\hline
\end{tabular}

Findings indicate that in excellent classes the percentage of students with 2 or 3 dominant intelligences is higher than the percentage of students with 2 or 3 dominant intelligences in ordinary classes. More importantly, this is not just a logical and linguistic intelligence, but also all types of intelligences, such as spatial, musical, kinetic and others (Table 6). 
Table 7. Percentage of multiple intelligences in dominant levels

\begin{tabular}{lllll}
\hline Type of intelligence & $\begin{array}{l}\text { Percentage of students } \\
\text { ordinary classes }\end{array}$ & $\begin{array}{l}\text { in } \\
\text { Percentage of } \\
\text { excellent classes }\end{array}$ & student in \\
\hline Linguistic / Verbal & $6.3 \%$ & $8 \%$ & \\
Logical / Mathematical & $43.1 \%$ & $67 \%$ & \\
Musical & $39 \%$ & $57 \%$ & \\
Spatial & $14.7 \%$ & $27 \%$ & \\
Bodily Kinesthetic & $40 \%$ & $27 \%$ & \\
Interpersonal & $45.2 \%$ & $19 \%$ & \\
Intrapersonal & $23.1 \%$ & $43 \%$ & \\
Spiritual / environmental & $21 \%$ & $35 \%$ & \\
\hline
\end{tabular}

\section{Case Study Limitations}

As stated above, the development of dominant intelligences among students is highly dependent on different factors, such as gender, age, family status, parental education, parental involvement, academic achievement, and others (Tsai, 2016). This case study was done in a single school in the center of the country. Residential areas in the city are characterized by a socioeconomic level of residents, and cultural and religious aspects. These findings do not characterize the entire student population in the seventh grade. Additionally, the gender of the students was not examined. In order to obtain more meaningful data, additional background variables that exist in the given student population must be considered.

Another limitation important to emphasize is the length of the questionnaire. The questionnaire itself had 80 questions and the filling time of the questionnaire was a challenge for the learners (especially for learners with learning difficulties). During the analysis of the questionnaire, several students, who did not take the questionnaire seriously, were excluded.

\section{Conclusions and Applications for the Future}

According to the findings obtained in this case study, we reach several conclusions:

\subsection{Dominant Intelligence and Success in Schooling}

The two dominant intelligences that were measured and influenced high achievement in the education system are not linguistic and logical, but only logical-mathematical. The findings also show that linguistic intelligence is not a dominant intelligence among students (both successful and unsuccessful). The two excellent classes are characterized by logical dominant intelligence, in terms of academic achievement. In the Moffet class, approximately $53.5 \%$ of students have logical intelligence as the dominant in the first level dominance, compared to ordinary classes, where only $23.1 \%$ of all students have the same dominant intelligence.

The case study data indicate that linguistic-verbal intelligence is not the intelligence that influences success in school. In Moffet class, the percentage of students with a linguistic dominant intelligence as first of dominance level is $1.6 \%$, and in ordinary classes is $3.1 \%$. The percentage of students in the case study population with linguistic intelligence as dominant at first level of dominance is relatively low $-2.5 \%$. Given the findings, it can be noticed that only one intelligence indicates success in studies - the logical-mathematical intelligence.

\subsection{The Multitude of Personal Dominant Intelligences}

The question was: Can multiple dominant intelligences, at least at one of first or second level of dominance, predict or indicate success in school? In response to the question, we analyzed the responses in the questionnaire and examined the amount of intelligences in the first and second level of dominance in ordinary and excellent classes. The findings indicate that among the high achievement learners, the amount of dominant intelligences is higher on at least one of the levels. We have seen that there are students with three dominant intelligences (maximum number), two dominant intelligences and one dominant intelligence (minimum number). The questionnaire data indicate that there is a significant difference between ordinary and excellent class learners: $2.2 \%$ of ordinary class students have equally dominant three intelligences, at least in one of the dominance levels (1-st and 2-ed); the percentage of students in excellent classes with three dominant intelligences in at least one of the levels is $22.2 \%$. 


\section{Future Research}

Even though this is only a case study, data indicates that students' dominant intelligences change because of the changes in the environments in which learners are located. Some intelligences are not relevant for educational systems, and some intelligences are not reflected in teaching approaches and strategies. Following the findings, we will be able to offer several suggestions for further action.

\subsection{Mapping Students' Intelligences}

A questionnaire built on available and free systems was sent to students. Schools nowadays have learning management systems, which can be used for sending the questionnaire to learners. Analyzing the questionnaire responses did not take much time and did not require much knowledge in the field of informational applications. Simple data processing in the Excel application can quickly indicate the dominant intelligences of learners. Mapping learners' intelligences will facilitate learning processes and learning skills to adapt teaching approach to the learner's dominant intelligence. It is important for both teacher and student to be aware of the most effective learning style for the student (Sener, 2018 \& Cokcaliskan). The theory of multiple intelligences can be applied through teaching approaches, teaching strategies, teaching methods and learning. The use of instruction tailored to the MI theory contributes to the development of logical, critical and creative thinking abilities, as well as the development of high levels of thinking (Calik \& Birgil, 2013).

\subsection{Multiple Dominant Intelligences}

The purpose of teaching is to equip learners with skills related to all learning styles and dominant intelligence, regardless the personal preference (Felder \& Brent, 2005). As students learn different learning styles, the higher the students' motivation for learning, the higher will be the achievement. Moreover, the development of dominant intelligences among students is highly dependent on and influenced by many factors (Tsai, 2016). As students grow and become exposed to different curricula, so do dominant intelligences. The use of social networks and social communication in the teaching process is an alternative to the traditional form of education and can contribute to the development of some intelligences, such as verbal or interpersonal (Yavich, 2013). The more we can develop the greater number of personal dominant intelligences among learners, the more students will develop as more independent, curious and capable learners.

\section{References}

Barrington, E. (2004). Teaching to student diversity in higher education: How multiple intelligence theory can help. Teaching in Higher Education, 9(4), 421-434. https://doi.org/10.1080/1356251042000252363

Bordei, S. (2017). How can one possibly determine the multiple intelligences? Journal Plus Education, 18(2), 204-212. https://doi.org/10.24250/jpe/2/2017/SB

Campbell, L., Campbell, B., \& Dickinson, D. (1996). Teaching \& Learning through Multiple Intelligences. Boston, MA, Allyn \& Bacon.

Calik, B., \& Birgili, B. (2013) Multiple Intelligence Theory for Gifted Education: Criticism and Implications. Journal for the Education of the Young Scientist and Giftedness, 1(2), 1-12. https://doi.org/10.17478/JEYSG.201329002

Felder, R'., \& Brent, R. (2005). Understanding Student Differences. Journal of Engineering Education, 94(1), 57-72. https://doi.org/10.1002/j.2168-9830.2005.tb00829.x

Gardner, H. (1983). Frames of mind: The theory of multiple intelligences. U.S.A: Basic Books.

Gardner, H. E. (2000; 1999) Intelligence reframed: Multiple intelligences for the 21st century. New York: Basic Books.

Gouws, F. E. (2007) . Teaching and Learning Through Multiple intelligences in the Outcomes-based Education Classroom. Africa Education Review, 4(2), 60-74. https://doi.org/10.1080/18146620701652705

Green, A. L., Hill, A. Y., Friday, E., \& Friday, S. S. (2005). The use of multiple intelligences to enhance team productivity. Management Decision, 43(3), 349-359. https://doi.org/10.1108/00251740510589742

Jena, R. K. (2018). Predicting students' learning style using learning analytics: a case study of business management students from India. Behavior \& Information Technology, 37(10-11), 978-992. https://doi.org/10.1080/0144929X.2018.1482369 
Sternberg, R. J. (2003). Creative Thinking in the Classroom. Scandinavian Journal of Educational Research, 47(3). https://doi.org/10.1080/00313830308595

Leffler, E. (2009). The Many Faces of Entrepreneurship: A Discursive Battle for the School Arena. European Educational Research Journal, 8(1), 104-116. https://doi.org/10.2304/eerj.2009.8.1.104

McKenzie, W. (2002). Multiple intelligence sand instructional technology: A Manual for every mind. Eugene, OR: International Society for Technology in Education.

Politis, D. (2005). The Process of Entrepreneurial Learning: A Conceptual Framework. Entrepreneurship Theory and Practice, 29(4), 399-424. https://doi.org/10.1111/j.1540-6520.2005.00091.x

Sener, S., \& Cokcaliskan, A. (2018). An Investigation between Multiple Intelligences and Learning Styles. Journal of Education and Training Studies, 6(2), 125-132. https://doi.org/10.11114/jets.v6i2.2643

Stanford, P. (2003). Multiple Intelligence for Every Classroom. Intervention in School and Clinic, 39(2), 80-85. https://doi.org/10.1177/10534512030390020301

Sternberg, R. J. (2012). The assessment of creativity: An investment-based approach. Creativity Research Journal, 24(1), 3-12. https://doi.org/10.1080/10400419.2012.652925

Tirri, K., \& Nokelainen, P. (2008). Identification of multiple intelligences with the Multiple Intelligence Profiling Questionnaire III. Psychology Science, 50(2), 206.

Tsai, M. Y. (2016). Research on Multiple Intelligences of Junior High School Students with Different Background $\begin{array}{lllll}\text { Variables. Journal of } & \text { Modern }\end{array}$ https://doi.org/10.15341/jmer(2155-7993)/01.06.2016/002

Weller, L. D. (1999). Application of the multiple intelligences' theory in quality organizations. Team Performance Management, 5(4), 136. https://doi.org/10.1108/13527599910283493

Wilson, S. D. (2018). Implementing co-creation and multiple intelligence practices to transform the classroom experience. Contemporary Issues in Education Research (CIER), 11(4), 127-132. https://doi.org/10.19030/cier.v11i4.10206

Yavich, R. (2013). Social networks and students. Research Journal of Management Sciences, 2(2), 1-2.

\section{Copyrights}

Copyright for this article is retained by the author(s), with first publication rights granted to the journal.

This is an open-access article distributed under the terms and conditions of the Creative Commons Attribution license (http://creativecommons.org/licenses/by/4.0/). 